toin (D.P.H.) and of reduced levels of serum and C.S.F. folate. In weanling rats placed on a folate-deficient diet profound falls of serum and tissue folate were observed, in contrast to cerebral folate concentrations which were maintained within the normal range. A similar reduction in serum and tissue folate concentrations was demonstrated in rats administered toxic doses of D.P.H. daily for up to 120 days together with a folate deficient diet; in the presence of substantial serum and tissue concentrations of D.P.H., no significant change in cerebral folate levels was observed. Tissue folate and D.P.H. concentrations were determined in cats rendered ataxic by the daily oral administration of D.P.H. for one to four weeks. In the presence of moderate depression of the serum, tissue, and C.S.F. folate concentrations, only mino changes were demonstrated in regional cerebral folate activity. Cats receiving D.P.H together with folic acid supplements also exhibited ataxia in the presence of substantial increases in serum tissue and C.S.F. folate and a minor increase in cerebral folate concentration.

These findings indicate that D.P.H.induced ataxia in cats and the prolonged administration of D.P.H. to rats are not associated with significant alterations of cerebral folate concentration. The ability of D.P.H. to raise, with low toxicity, the convulsant threshold for electrical stimuli in cats led to its successful introduction in the management of epilepsy 30 years ago. ${ }^{4}$ Although the anticonvulsant action of D.P.H. was not investigated in the studies described, the maintenance of normal cerebral folate activity in the presence of D.P.H suggests that this therapeutic action is not mediated through change in cerebral folate concentration.

D.P.H.-induced folate deficiency appears to be a complication unrelated to any therapeutic benefit. Whether the insidious neuropathy, unresponsive to folic acid supplements, ${ }^{5}$ and mental deterioration observed in some epileptic subjects are related to an ultimate reduction in cerebral folate activity or to a direct neurotoxic action of D.P.H. on neural tissue has still to be defined. The unique case of folic acid deficiency from malabsorption with mental retardation, epilepsy, and basal ganglia calcification reported by Lanzkowsky et al, has confirmed the importance of cerebral transport mechanisms in the maintenance of cerebral folate activity in man.-I am, etc.,

$$
\begin{aligned}
& \text { Royal United Hospital, } \\
& \text { Bath. }
\end{aligned}
$$

\section{D. Allen.}

\section{REFERENCES}

1 Allen, C. D, and Klipstein, F. A., Neurolosy (Minneapolis) $1970,20,403$

2 Allen, C. D., and Goldblatt, D., 1970, unpublished. 3 Allen, C. D., and Klipstein, F. A.. Transaction of the American Neurological Association, in

4 Putnam, T. J., and Merritt, H. H., Science, 1937, 85. 525.

Horowitz, S. J., Klipstein, F. A., and Lovelace,
R. E., Lancet, 1968, 563 .

Lanzkowskv, P., Erlandson, M. E., and Bezan,
A. I., Blood, 1969, 34, 452.

\section{Skin Disease and the Gut}

SIR,-I read with interest your leading article on the above subject (1 August, p 240). On going to Singapore where tropical sprue occurs with some frequency in the
European population ${ }^{1}$ I carried out a survey of skin diseases occurring for the first time since arrival in the tropics to see whether intestinal malabsorption, which is a cardinal feature of sprue, was associated with any one skin disease. Various abnormalities of the skin have been described in association with tropical sprue and idiopathic steatorrhoea which include pigmentation ${ }^{2}$ and psoriasiform eruptions. ${ }^{3}$

In my survey I found one group of 35 patients, mostly women, presenting with a patchy eczematous dermatitis of hands and feet, in 17 of whom there was evidence from absorption studies and jejunal biopsy of an enteropathy consistent with early tropical sprue. The enteropathy and the skin disease responded to therapy with folic acid and broad spectrum antibiotics normally given for tropical sprue.

I was also able to substantiate the findings of England and O'Brien ${ }^{4}$ that apparently normal Europeans in Singapore had normal mucosae, also that there was no enteropathy associated with tropical impetigo, prickly heat, and acne in the tropics. ${ }^{5}$ I am, etc.,

\section{Dermatology Department,
British Military Hospital, Munster. B.F.P.O. 17}

\section{REFERENCES}

O'Brien, W., and England, N. W. J., British Medical fournal, 1966, 2, 115

Manson-Bahr. P, and Willoughby, H., Quarterly 7ournal of Medicine, 1930, 23, 411

Cooke, W. T., Peeney, A. L. P. and Hawkins, 5 9.

Fryland. N. W. J., and O'Brien, W., Gut, 1966 7. 128

Hindson, T. C., Archives of Dermatology (in press)

\section{George III and the Mad-business}

SIR,-Dr. M. M. Salzmann (15 August, p 406) questions the recent opinions that George III's "insanity" was due to porphyria rather than being idiopathic. This is an interesting academic argument that, no doubt, experts will continue to pursue.

However, Dr. Salzmann, quite unwittingly, does raise a completely different issue. Believing that King George's insanity was idiopathic, the writer apologizes for his beliefs by writing "without wishing to recast any slur on our monarchy's ancestors" (my italics). I feel that a strong undercurrent of this sentiment lies behind much of the recent interest in George III's illness. In other words, if the illness was due to porphyria then the Monarch was an unfortunate man suffering from organic disease, albeit not recognized at the time. On the other hand, if the illness cannot be identified with a biochemical abnormality, then in some way King George III was deserving of censure and stigmatized on that account.

What a lot of nonsense this is. Who knows that medical science will not at some future time find a structural or biochemical basis for all mental illness? The situation is especially ironic because the national indignation aroused by the treatment meted out to George III led to the appointment by the House of Lords of a committee of inquiry. Recommendations resulted in humane reforms in the treatment of mental illnesses, but old attitudes die hard. I raise this point because $I$ assume that the writer of the letter is a psychiatrist. As long as psychiatrists are prepared to perpetuate this irrational prejudice then the longer will their specialty be a cinderella in the N.H.S.- am, etc.,

Philip Jacobs.

Solihull,

It is apparent that on average patients sleep reasonably well without any hypnotic better with a placebo, and best with a hypnotic and differences are small. In view of the risk of dependence, clearly it is important that hypnotics given to patients in hospital should be discontinued at the first opportunity, and before discharge. The few nights of disturbed sleep following withdrawal would then be experienced during the period of convalescence in hospital Instances where withdrawal is distressing may be helped by the use of a placebo.We are, etc.,

M. R. BOND. I. B. Pearson.

C. P. SEAGER.

Department of Psychiatry,
University of Sheffield, Yorks. 